\title{
Spectrophotometric Determination of Trace Amounts of Iodide by Its Catalytic Effect on the Chlorpromazine-Hydrogen Peroxide Reaction
}

\author{
Takashi TomiYasu, Hayao SaKamoto and Norinobu YoneHARA \\ Department of Chemistry, Faculty of Science, Kagoshima University, Kagoshima 890, Japan
}

\begin{abstract}
A catalytic photometric method for the determination of trace amounts of iodide is proposed. In the presence of iodide, chlorpromazine is oxidized by hydrogen peroxide in a sulfuric acid solution to form a red intermediate, which is further oxidized to a colorless compound. The reaction is followed by measuring the increase in the absorbance at $525 \mathrm{~nm}$; the maximum absorbance is obtained on an absorbance-time curve at a given reaction time. Since the maximum value increases with an increase in the iodide concentration, this value is used as a parameter for the iodide determination. Under the optimum experimental conditions (1.0 $\times 10^{-3} \mathrm{M}$ chlorpromazine, $1.5 \mathrm{M}$ sulfuric acid, $2.0 \mathrm{M}$ hydrogen peroxide, $30^{\circ} \mathrm{C}$ ), iodide in the range $0.2-10 \mu \mathrm{g} \mathrm{l}^{-1}$ can be determined. The relative standard deviations are $0.8,2.6$ and $4.2 \%$ for $6.0,2.0$ and $0.6 \mu \mathrm{g} \mathrm{l}^{-1}$ iodide, respectively. Although iodate shows the same catalytic effect as iodide at the same concentration as iodine, free iodine shows a somewhat lower catalytic effect. The procedure has been applied to the determination of iodide in natural water samples.
\end{abstract}

Keywords Iodide determination, catalytic method, photometry, chlorpromazine, hydrogen peroxide

Because of the growing need for highly sensitive traceanalysis methods, catalytic methods have been receiving increasing attention. A number of catalytic methods based on different indicator reactions have been proposed for iodide determination. ${ }^{1-7}$ Chlorpromazine hydrochloride (CPH) is oxidized to form a red intermediate, which has been designated as being a free radical having an absorption maximum at $525 \mathrm{~nm}{ }^{8}$ This reagent was first used by Cordoba $e t$ al. as an indicator reagent in kinetic analysis, based on the vanadium(V)-catalyzed oxidation of $\mathrm{CPH}$ by bromate in a phosphoric acid solution. ${ }^{9}$ They also applied this indicator reaction to the catalytic determination of iodide in biological samples. ${ }^{10}$ This method, however, exhibited a higher reagent blank, and was not sufficiently sensitive for the analysis of such samples as natural water having fairly low iodide concentrations, often below $1 \mu \mathrm{g} \mathrm{l}^{-1}$; its detection limit was only $5 \mu \mathrm{g} \mathrm{l}^{-1}$.

In our investigation of an iodide-catalyzed oxidation of $\mathrm{CPH}$ by different oxidants (hydrogen peroxide, Chloramine $T$, sodium peroxoborate and potassium bromate) in several acidic (hydrochloric, nitric, sulfuric and acetic acids) media, it was found that when hydrogen peroxide was used as an oxidant in sulfuric acid solution, only a slight coloration caused by the oxidation of $\mathrm{CPH}$ was observed in the absence of iodide; this color formation reaction, however, was considerably accelerated by trace amounts of iodide. We thus developed a kinetic spectrophotometric method for the determination of iodide, based on its catalytic effect on the CPH-hydrogen peroxide reaction, and also investigated kinetically this catalyzed reaction. The resulting method is both highly sensitive and reproducible: as little as $0.2 \mu \mathrm{g} \mathrm{l}^{-1}$ of iodide can be determined with reasonable reproducibility. This method has been successfully applied to the determination of iodide in natural water samples.

\section{Experimental}

\section{Apparatus and reagents}

A Japan Spectroscopic Co. Ubest-35 spectrophotometer was used with a thermostated cell holder $\left(30 \pm 0.1^{\circ} \mathrm{C}\right)$ coupled with a Japan Spectroscopic Co. PTL3965 plotter. The temperature was controlled with a Shibata Science Instrument Co. control unit (CU-85) circulating thermostat bath. For the reaction, $1 \mathrm{~cm}$ glass cells were used. The reaction was initiated by the injection of a hydrogen peroxide solution from a Gilson Pipetman (Model P-1000). For mixing, a remote-controlled magnetic Acrobat stirrer (MS Instrument, Osaka, Japan) was installed at the side of cell holder in the spectrophotometer.

Pure water was prepared by purifying distilled water with a Millipore Milli-Q SP system just befor use.

Reagent-grade chemicals were used throughout.

A CPH solution $(0.050 \mathrm{M})$ was prepared by dissolving $0.888 \mathrm{~g}$ of chlorpromazine hydrochloride in water and diluting to $50 \mathrm{ml}$ with water. 
A commercial $31 \%$ solution of hydrogen peroxide $(10.2 \mathrm{M})$ was used. The concentration of this solution was checked by permanganate titration.

A potassium iodide stock solution $(0.1 \mathrm{M})$ was standardized using Volhard's method. Working solutions were prepared by suitable dilution with water.

A potassium iodate stock solution $\left(1000 \mathrm{mg} \mathrm{l}^{-1}\right.$ as iodine) was prepared by dissolving $0.8475 \mathrm{~g}$ of potassium iodate in water and diluting to $500 \mathrm{ml}$ with water. Working solutions were prepared by diluting this solution.

An iodine $\left(\mathrm{I}_{2}\right)$ stock solution was prepared by dissolving $50 \mathrm{mg}$ of elemental iodine in $200 \mathrm{ml}$ of water. The concentration of this solution was determined spectrophotometrically at $350 \mathrm{~nm}$ in the presence of excess iodide in an acidic solution just before use. Working solutions were prepared by diluting this solution.

A sulfuric acid $(9.0 \mathrm{M})$ solution was prepared by diluting concentrated sulfuric acid with water.

\section{Recommended procedure}

To $9.0 \mathrm{ml}$ of sample solution in a glass-stoppered tube, $0.30 \mathrm{ml}$ of $0.050 \mathrm{M} \mathrm{CPH}$ solution and $2.5 \mathrm{ml}$ of $9.0 \mathrm{M}$ sulfuric acid were added in this order and thoroughly mixed. This solution was kept at $30^{\circ} \mathrm{C}$ in a water bath for about $15 \mathrm{~min}$; a $1.6 \mathrm{ml}$ aliquot was then taken into a $1 \mathrm{~cm}$ glass cell. The cell was placed in the holder at $30^{\circ} \mathrm{C}$ and the contained solution magnetically stirred. The reaction was initiated by the injection of $0.40 \mathrm{ml}$ of a 10.2 M hydrogen peroxide solution $\left(30^{\circ} \mathrm{C}\right)$. The increase in absorbance of the red intermediate at $525 \mathrm{~nm}$ was recorded against a pure-water reference.

\section{Results and Discussion}

Oxidation of $\mathrm{CPH}$ by hydrogen peroxide and the accelerating effect of iodide on the color formation

In the presence of iodide, $\mathrm{CPH}$ is oxidized by hydrogen peroxide in a sulfuric acid solution to form a red free radical, which is further oxidized to a colorless compound. The reaction can be followed by measuring the increase in absorbance of the red intermediate at $525 \mathrm{~nm}$. As can be seen in Fig. 1, the absorbance increases with an increase in the reaction time, and reaches a maximum value at a given time after adding the hydrogen peroxide solution. After the curves kept maximum values for $20-30 \mathrm{~s}$, the absorbances decrease rather slowly. Since the maximum absorbance increases with an increase in the iodide concentration, this value was used as a parameter for the iodide determination.

Despite the fact that the red intermediate only very slowly decolorized, the absorbance-time curves for the blank and the lower iodide concentrations also reached a maximum at fairly low absorbance. According to this observation, the following behaviors were suspected. Chlorpromazine may not only be consumed by the

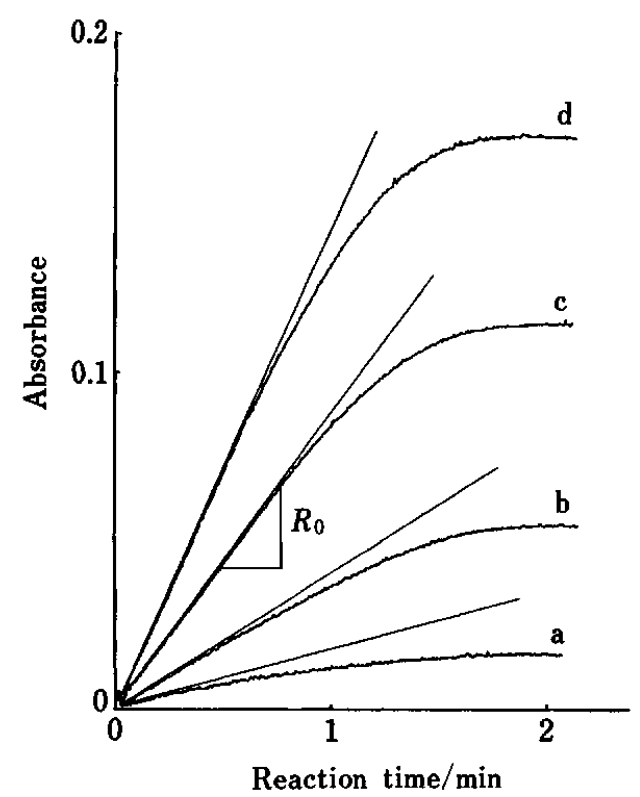

Fig. 1 Absorbance-vs.-time curves for the $\mathrm{CPH} /$ hydrogen peroxide reaction. Concentration of iodide $\left(\mu \mathrm{gl}^{-1}\right)$ : (a) 0 , (b) 2.0 , (c) 6.0 , (d) 10.0 . Conditions: $1.0 \times 10^{-3} \mathrm{M} \mathrm{CPH,}$ $1.5 \mathrm{M}$ sulfuric acid, $2.0 \mathrm{M}$ hydrogen peroxide, $30^{\circ} \mathrm{C} . \quad R_{0}$ : $\Delta$ (absorbance) $/ \Delta(\mathrm{sec})$ at reaction time zero was used as a measure of the initial reaction rate.

colorformation reaction, but also consumed simultaneously by a reaction without any coloration competing with the former one. Iodide accelerates the former reaction. In the absence of iodide a large portion of CPH is consumed in the latter reaction, resulting in the development of the maximum on the reaction curve, even in a very low absorbance. This suspicion was confirmed by the following experiments, the results of which are shown in Fig. 2. When the iodide solution was added to the reaction mixture for an uncatalyzed reaction (curve A) at a certain time after initiating the reaction (arrow a), an additional increase in the absorbance took place; its value also reached a maximum (curve $A^{\prime}$ ). However, this maximum absorbance (circle d) did not reach a value (circle c) equivalent to the concentration of the added iodide. The maximum value decreased with an increase in the time interval between the start of reaction and the addition of iodide (curve $\mathrm{C}$ ); no additional increase in the absorbance was observed upon adding the iodide solution when the reaction curve reached the maximum (circle e). When the CPH solution was added to the reaction mixture for the iodide-catalyzed reaction (curve B) at the maximum on the reaction curve (arrow b), an additional increase in the absorbance also took place, and the reaction curve showed a maximum having an appropriate value for the iodide concentration contained (curve $B^{\prime}$ ). These results suggest that at the maximum absorbance on the reaction curves $\mathrm{CPH}$ has been exhausted and, thus, its coloration has ceased, even at a fairly low absorbance, such as in the case of the blank. 


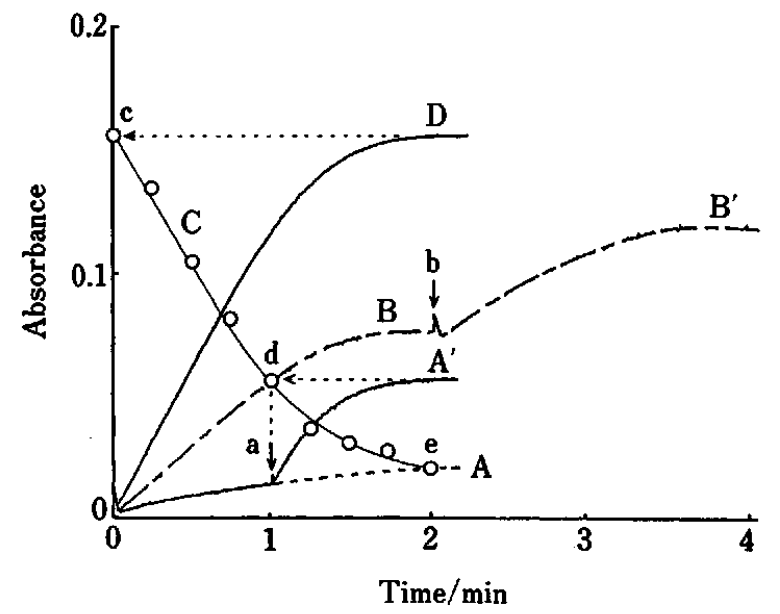

Fig. 2 Effect of the subsequent addition of iodide or CPH to the reaction mixture. Concentration of iodide in reaction mixture (M): (A) 0 , (B) $1.9 \times 10^{-8}$, (D) $3.9 \times 10^{-8}$; other conditions as in Fig. 1. A $0.010 \mathrm{ml}$ of $7.9 \times 10^{-6} \mathrm{M}$ iodide solution was added at arrow a to give the iodide concentration in the reaction mixture to be $3.9 \times 10^{-8} \mathrm{M}$; a $0.041 \mathrm{ml}$ of $0.050 \mathrm{M} \mathrm{CPH}$ solution was added at arrow b. See text for curves $\left(A^{\prime}\right),\left(B^{\prime}\right)$ and $(C)$; circles $(c),(d)$ and (e).

\section{Kinetic study of the color formation reaction}

Since the oxidation of CPH with hydrogen peroxide proceeds by three parallel pathways, a kinetic investigation of color formation reaction was carried out by the initial-rate method, in which the initial slopes of the reaction curves $\left(\mathrm{d}(\mathrm{Abs}.) / \mathrm{d} t=R_{0}\right)$ are manually determined and then used as a measure of the initial reaction rate. A kinetic study of the catalyzed and uncatalyzed reactions resulted in the following rate law:

$$
R_{0}=k_{\mathrm{c}}\left[\mathrm{H}_{2} \mathrm{O}_{2}\right]\left[\mathrm{H}^{+}\right]\left[\mathrm{I}^{-}\right]+k_{0}[\mathrm{CPH}]\left[\mathrm{H}_{2} \mathrm{O}_{2}\right]\left[\mathrm{H}^{+}\right]
$$

Here, $k_{\mathrm{c}}$ and $k_{0}$ are the observed rate constants for the catalyzed and uncatalyzed reactions, respectively. Although the color formation was first order with respect to $\mathrm{CPH}$ in the absence of iodide, the catalyzed reaction was zero order with respect to CPH. This behavior suggests that the color formation of $\mathrm{CPH}$ in the catalyzed reaction proceeds rapidly after the rate-determining step. The following mechanism for the catalyzed reaction is proposed as the most plausible one that is consistent with the above empirical rate law:

$$
\begin{aligned}
& \mathrm{H}^{+}+\mathrm{H}_{2} \mathrm{O}_{2} \rightleftarrows \mathrm{HOOH}_{2}^{+} \text {(fast), } \\
& \mathrm{I}^{-}+\mathrm{HOOH}_{2}+\mathrm{H}_{2} \mathrm{O}+\mathrm{HOI} \text { (slow), }
\end{aligned}
$$

and

$$
\mathrm{CPH}+\mathrm{HOI} \longrightarrow \mathrm{P}_{(\text {red })}+\mathrm{I}^{-} \quad \text { (fast). }
$$

The second step is the rate-determining one and the intermediate HOI oxidizes $\mathrm{CPH}$ to its red intermediate $\mathbf{P}_{(\text {red) }}$, regenerating iodide.
From an Arrhenius plot in the $15-40^{\circ} \mathrm{C}$ temperature range, the activation energy for a catalyzed reaction was calculated to be $37.4 \mathrm{~kJ} \mathrm{~mol}^{-1}$; that for an uncatalyzed reaction was $65.1 \mathrm{~kJ} \mathrm{~mol}^{-1}$.

Details concerning kinetic and mechanistic studies will be published elsewhere.

\section{Effects of the reaction variables}

The influence of temperature on the maximum absorbance for both catalyzed and uncatalyzed reactions was studied in the $15-40^{\circ} \mathrm{C}$ range, under conditions otherwise as in the recommended procedure. The values remained approximately constant in the presence of iodide, while those for the blank rose slightly with an increase in temperature. Although the higher sensitivity was, therefore, obtained at lower temperatures, there was only a slight increase in the sensitivity upon lowering the temperature. A temperature of $30^{\circ} \mathrm{C}$ was chosen because of the convenience for adjusting the temperature throughout the year. The time required for the absorbance to reach a maximum was gradually reduced with temperature from $340 \mathrm{~s}$ at $15^{\circ} \mathrm{C}$ to $70 \mathrm{~s}$ at $40^{\circ} \mathrm{C}$.

Figure 3(a) shows that there is a complicated relation between the sulfuric acid concentration and the maximum absorbance. In this reaction system CPH is consumed by three parallel pathways: catalyzed and uncatalyzed color formation reactions, and a side reaction without coloration. Probably, the variation in the hydrogen ion concentration affects the reaction rate by each pathway to a different extent, thus causing the complicated variation in the amount of $\mathrm{CPH}$ available to the color formation. A sulfuric acid concentration of $1.5 \mathrm{M}$ was chosen, since it gave the highest sensitivity and the lower blank. The maximum absorbance for the blank was lowered with increasing hydrogen peroxide concentration (Fig. 3(b)). This is probably because an increase in the hydrogen peroxide concentration increases the rate of the side reaction, thus reducing the $\mathrm{CPH}$ concentration available to color formation. The effect for the catalyzed reaction gradually became less pronounced with increasing iodide concentration. A hydrogen peroxide concentration of $2.0 \mathrm{M}$ was chosen by considering the sensitivity and the volume of this reagent solution to be used in the procedure. The time required for the absorbance to reach a maximum decreased with increasing concentration of each of these reagents (sulfuric acid and hydrogen peroxide).

The maximum absorbance rose with increasing $\mathrm{CPH}$ concentration in both the presence of iodide and in its absence. Since the effect was more pronounced for a catalyzed reaction, a higher sensitivity can be realized at higher CPH concentrations (Fig. 3(c)). However, at higher $\mathrm{CPH}$ concentrations the influence of interfering substances increased significantly, due to the susceptibility of $\mathrm{CPH}$ to react with many oxidizing materials. When a $\mathrm{CPH}$ solution with a higher concentration, along with sulfuric acid, was added to natual water samples, in many samples color formation 


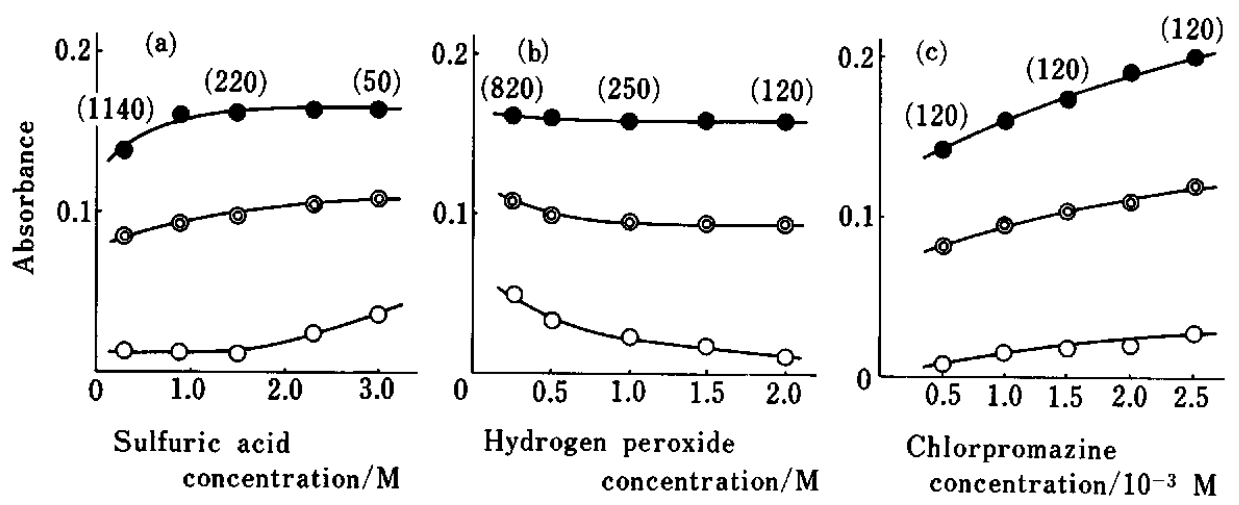

Fig. 3 Effect of the experimental variables on the catalytic effect of iodide ( $O$ blank, $\odot 5.0 \mu \mathrm{g} \mathrm{l}^{-1}, \odot 10.0 \mu \mathrm{g} \mathrm{l}^{-1}$ ): (a) sulfuric acid concentration; (b) hydrogen peroxide concentration; (c) CPH concentration; (sec): times required for the absorbances to reach a maximum. Conditions as in Fig. 1, except for the reagent indicated on abscissa and the hydrogen peroxide concentrations of $1.25 \mathrm{M}$ in (a).

occurred to a measurable extent prior to the addition of a hydrogen peroxide solution, causing serious errors in the iodide determinations; thus, CPH in the higher concentrations significantly vitiates the applicability of the method to real samples. Hence, a lower CPH concentration of $1.0 \times 10^{-3} \mathrm{M}$ was adopted. No variation in the time required for the absorbance to reach a maximum was observed by varying the $\mathrm{CPH}$ concentration.

\section{Calibration graphs and reproducibility}

A series of standard solutions of iodide was treated as in the recommended procedure. The resulting graph showed a slightly negative deviation (Fig. 4,0 ). The relative standard deviations for 11 replicate determinations of $6.0,2.0$, and $0.6 \mu \mathrm{g} \mathrm{I}^{-1}$ of iodide were $0.8,2.6$ and $4.2 \%$, respectively; it was $10.2 \%$ even at concentrations as low as $0.2 \mu \mathrm{g} \mathrm{l}^{-1}$, which was the lowest concentration that could be determined (Fig. 4, inset)

\section{Catalytic effects of iodide and free iodine}

Iodate showed the same catalytic effect (Fig. 4, ) as did iodide in the same concentration as iodine, while the catalytic activity of free iodine (Fig. 4, ๑) was slightly lower than that of iodide. Mercury(II) ion inhibits the catalytic activity of iodide at the same concentration level as iodide; the larger is the mercury(II) concentration, the lower is the activity of iodide, and excess mercury(II) completely inhibits the iodide activity. This inhibition probably results from the formation of a complex between mercury(II) and iodide. Iodate was also inhibited by mercury(II) ions to the same extent as iodide, indicating that iodate has been reduced to iodide by $\mathrm{CPH}$ and is then introduced into the catalytic cycle. Although free iodine may also be reduced by $\mathrm{CPH}$, and then act as a catalyst, the observed negative deviation of the calibration graph for free iodine from that for iodide presumably results from the conversion of a portion of free iodine to a catalytically inactive species, such as the

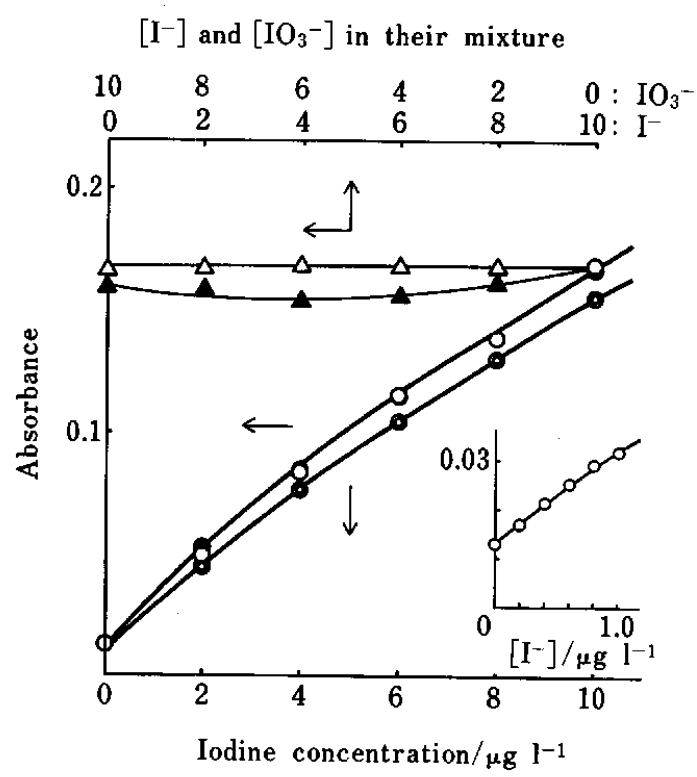

Fig. 4 Calibration graphs and effect of order of reagent addition. Conditions as in Fig. $1 ;(0)$ iodide; (०) iodate; (๑) free iodine. Reagents were added to the mixture of iodide and iodate in the following order: $(\triangle) \mathrm{CPH} /$ sulfuric acid; $(\Delta)$ sulfuric acid/CPH. The inset provides detail for the lower concentration range of curve for iodide $(O)$.

iodinated product of $\mathrm{CPH}$, or its escape from the strong acidic solution. If samples contain free iodine, the results obtained by the present procedure should be somewhat lower.

\section{Effect of order of reagent addition}

In applying this reaction system to mixtures of iodide and iodate, it was observed that the results for the mixtures are affected by varying the order of reagent addition. When a CPH solution and sulfuric acid were added to the mixture in the same order, as in the 
recommended procedure, the obtained absorbances remained constant at the expected value, regardless of the ratios of iodide and iodate (Fig. 4, $\Delta$ ). However, when sulfuric acid was first added to the mixture, followed the addition of a CPH solution, there was an apparent decrease in the value obtained from that by the recommended procedure; the value varied with varying ratio of iodide and iodate (Fig. 4, $\Delta$ ). When solutions containing free iodine were analyzed by this order of reagent addition, the obtained results were less reproducible. This is presumably because, when sulfuric acid was first added to the mixture, iodide and iodate react partly with each other to form less reactive free iodine, as discribed above. The order of the addition of the reagents indicated in the recommended procedure was favorable for obtaining reproducible results.

\section{Effect of foreign ions}

The effect of various ions on the determination of $5 \mu \mathrm{gl}^{-1}$ iodide was examined. The following ions showed no interference, at least at the concentrations $\left(\mathrm{mg} \mathrm{l}^{-1}\right)$ shown in parentheses: $\mathrm{K}^{+}$and $\mathrm{Na}^{+}(2000)$; $\mathrm{NO}_{3}{ }^{-}$ (1500); $\mathrm{NH}_{4}{ }^{+}$and $\mathrm{Ca}^{2+}(1000) ; \mathrm{Mg}^{2+}(500) ; \mathrm{Ni}^{2+}, \mathrm{Zn}^{2+}, \mathrm{Cd}^{2+}$, $\mathrm{Sn}^{4+}, \mathrm{Mn}^{2+}, \mathrm{Al}^{3+}, \mathrm{Ce}^{3+}, \mathrm{As}(\mathrm{V}), \mathrm{Cl}^{-}, \mathrm{ClO}_{3}{ }^{-}, \mathrm{ClO}_{4}^{-}, \mathrm{CO}_{3}{ }^{2-}$, $\mathrm{C}_{2} \mathrm{O}_{4}{ }^{2-}$ and $\mathrm{CH}_{3} \mathrm{COO}^{-}(100) ; \mathrm{Cu}^{2+}, \mathrm{Pb}^{2+}, \mathrm{Sn}^{2+}, \mathrm{Sb}(\mathrm{III})$,
$\mathrm{Sb}(\mathrm{V}), \mathrm{SiO}_{4}{ }^{2-}, \mathrm{SO}_{3}{ }^{2-}$ and $\mathrm{PO}_{4}{ }^{3-}(10)$. The interfering ions are listed in Table 1 . Ions which are known to

Table 1 Effect of interfering ions on the deremination of $5.0 \mu \mathrm{g} \mathrm{l}^{-1}$ of iodide

\begin{tabular}{|c|c|c|}
\hline Ion added & Concn. $/ \mathrm{mg} \mathrm{1}^{-1}$ & $\mathrm{I}^{-}$found $/ \mu \mathrm{g} \mathrm{l}^{-1}$ \\
\hline $\mathrm{As}(\mathrm{III})$ & 10 & 4.3 \\
\hline V(IV) & 10 & 5.3 \\
\hline $\mathrm{F}^{-}$ & 10 & 5.4 \\
\hline Mo(VI) & 5 & 2.7 \\
\hline $\mathrm{Ba}^{2+}$ & 1 & 7.9 \\
\hline $\mathrm{Ce}(\mathrm{IV})$ & 1 & 7.2 \\
\hline W(VI) & 1 & 4.2 \\
\hline $\mathrm{Ag}^{+}$ & 0.1 & 0.9 \\
\hline $\mathrm{Fe}^{2+}$ & 0.1 & 6.6 \\
\hline $\mathrm{Fe}^{3+}$ & 0.1 & 6.7 \\
\hline $\mathrm{Cr}(\mathrm{VI})$ & 0.1 & 6.2 \\
\hline Mn(VII) & 0.1 & 7.1 \\
\hline $\mathrm{SCN}^{-}$ & 0.1 & 7.3 \\
\hline $\mathrm{Br}^{-}$ & 0.1 & 5.3 \\
\hline $\mathrm{S}_{2} \mathrm{O}_{3}{ }^{2-}$ & 0.1 & 3.2 \\
\hline $\mathrm{NO}_{2}^{-}$ & 0.01 & 5.6 \\
\hline $\mathrm{BrO}_{3}^{-}$ & 0.01 & 5.5 \\
\hline $\mathrm{S}^{2-}$ & 0.01 & 5.6 \\
\hline $\mathrm{Hg}^{2+}$ & 0.001 & 4.4 \\
\hline
\end{tabular}

Table 2 Determination of iodine in natural water samples

\begin{tabular}{|c|c|c|c|c|c|c|}
\hline \multirow{2}{*}{ Sample } & \multirow{2}{*}{$\begin{array}{c}\text { Dilution } \\
\text { (times) }\end{array}$} & \multirow{2}{*}{ Added $/ \mu \mathrm{g} \mathrm{l}^{-1}$} & \multirow{2}{*}{ Found $/ \mu \mathrm{g}^{1^{-1}}$} & \multirow{2}{*}{$\begin{array}{c}\text { Recovery, } \\
\%\end{array}$} & \multicolumn{2}{|c|}{ In sample $/ \mu \mathrm{g} \mathrm{l}^{-1}$} \\
\hline & & & & & Present method & Other method \\
\hline \multirow[t]{5}{*}{ River water I } & - & - & 0.45 & - & 0.45 & 0.55 \\
\hline & 2 & - & 0.28 & - & 0.56 & \\
\hline & 2 & 0.50 & 0.80 & 103 & & \\
\hline & 2 & 1.00 & 1.35 & 105 & & \\
\hline & & & & & av. 0.51 & \\
\hline \multirow[t]{7}{*}{ River water II } & - & $\ldots$ & 1.95 & - & 2.0 & 2.4 \\
\hline & 2 & - & 1.20 & - & 2.4 & \\
\hline & 5 & - & 0.40 & - & 2.0 & \\
\hline & 5 & 0.50 & 0.90 & 100 & & \\
\hline & 5 & 1.00 & 1.42 & 101 & & \\
\hline & 10 & - & 0.20 & - & 2.0 & \\
\hline & & & & & av. 2.1 & \\
\hline \multirow[t]{7}{*}{ River water III } & - & - & 3.03 & - & 3.0 & 3.9 \\
\hline & 2 & - & 1.55 & - & 3.1 & \\
\hline & 5 & - & 0.67 & - & 3.4 & \\
\hline & 5 & 0.50 & 1.15 & 98 & & \\
\hline & 5 & 1.00 & 1.65 & 99 & & \\
\hline & 10 & - & 0.33 & - & 3.3 & \\
\hline & & & & & av. 3.2 & \\
\hline \multirow[t]{5}{*}{ Rain water } & - & - & 0.39 & - & 0.39 & - \\
\hline & 2 & - & 0.20 & - & 0.40 & \\
\hline & 2 & 0.20 & 0.44 & 110 & & \\
\hline & 2 & 0.40 & 0.58 & 97 & & \\
\hline & & & & & av. 0.40 & \\
\hline
\end{tabular}

a. Catalytic (iron(III) thiocyanate) method, by which total iodine can be determined including free iodine and iodate. 
participate in redox reactions as either oxidizing or reducing agents cause serious interference. Mercury and silver ions seriously interfere by combining with iodide. These ions showed no interference at concentrations one order lower than those indicated in Table 1.

\section{Determination of iodine in natural water samples}

In order to test the reliability of the present method, it was applied to the determination of iodide in natural water samples. The determinations were made by using samples diluted at different times; the method was also checked by adding a known amount of iodide to the samples. The results are shown in Table 2. The values corrected for dilution showed good agreement, and good recoveries of added iodide were obtained ranging from 97 to $110 \%$ (mean $102 \%$ ). In a few of these examples, a slight coloration was observed upon the addition of the $\mathrm{CPH}$ and sulfuric acid solutions prior to the addition of hydrogen peroxide. However, the satisfactory results described above were obtained by subtracting the absorbance $(<0.05)$ measured before starting the reaction from the maximum absorbance finally obtained, and then evaluating the iodide concentration by using the resulting net value. The proposed method is quite suitable for determining iodide at very low concentrations.

These samples were also analyzed by the other method. As can be seen in Table 2, the results obtained by the proposed method tended to be somewhat lower than those obtained by the other one. This tendency may suggest that iodine in river water is partly present in the form of free iodine. The speciation of iodine in natural water samples is an interesting subject to be further investigated.

\section{References}

1. E. B. Sandell and I. M. Kolthoff, J. Am. Chem. Soc., 56, 1426 (1934).

2. E. B. Sandell and I. M. Kolthoff, Mikrochim. Acta [Wien], 1, 6 (1937)

3. N. Yonehara, Bull. Chem. Soc. Jpn., 37, 1101 (1964).

4. K. Oiwa, T. Kimura, H. Makino and Y. Kinoshita, Brnseki Kagaku, 17, 805 (1968).

5. S. Funahashi, M. Tabata and M. Tanaka, Anal. Chim. Acta, 57, 311 (1971).

6. E. Jungreis and I. Gedalia, Mikrochim. Acta [Wien], 1960, 145.

7. N. Yonehara, S. Kozono and H. Sakamoto, Anal. Sci, 1991, 229.

8. I. S. Forrest, F. M. Forrest and M. Berger, Biochim. Biophys. Acta, 29, 441 (1958).

9. M. H. Córdoba, P. Viñas and C. Sánchez-Pedreño, Analyst [London], 110, 1343 (1985).

10. P. Viñas, M. H. Cordoba and C. Sánchez-Pedreño, Talanta, 34, 351 (1987).

(Received February 20, 1992)

(Accepted March 23, 1992) 